\title{
Domain-specific effects of physical activity on the demand for physician visits
}

\author{
Simon Spika ${ }^{1} \cdot$ Friedrich Breyer $^{1}$
}

Received: 23 November 2019/Revised: 24 February 2020 / Accepted: 18 April 2020/Published online: 6 May 2020

(C) The Author(s) 2020

\begin{abstract}
Objectives To assess domain-specific effects of physical activity (PA) in the relationship with health care utilization and to investigate whether a measure that aggregates PA across domains (leisure, transport, work) is appropriate.

Methods Data were retrieved from a longitudinal cohort study conducted in Southern Germany (women $n=1330$, men $n=766$ ). The number of physician visits was regressed on total PA and on PA differentiated by the domains leisure time, travel time and working time in a negative binomial model.

Results For women, no association with physician visits is found for total PA, while high leisure time physical activity (LTPA) is associated with $22 \%$ more visits. The effect of high LTPA is statistically different from the effect of high total PA. For men, no significant associations are found for both measures.

Conclusions The specific, positive effect of high LTPA on physician visits among women shows that using an aggregate measure of PA is inappropriate for analyzing the relation between PA and health care utilization. Further, the positive relationship should be considered in attempts to promote physical activity.
\end{abstract}

Keywords Physical activity - Leisure time physical activity · Occupational physical activity · Health care utilization · Physician visits · Konstanz Life-Study

\section{Introduction}

Physical activity (PA) has been proven to be an important factor in the prevention of numerous chronical diseases (Bull et al. 2004; Maruti et al. 2008; Meisinger et al. 2007; Sundquist et al. 2005), and the biological mechanisms behind these benefits are well understood (Bouchard et al. 2012; Bull et al. 2004). As with each prevented case of illness the associated use of health care resources is avoided, PA is seen as a key modifiable factor in the struggle against ever rising health care expenditures.

However, besides these effects, which pertain more to a long-term relationship, there are also direct associations,

Electronic supplementary material The online version of this article (https://doi.org/10.1007/s00038-020-01376-5) contains supplementary material, which is available to authorized users.

Simon Spika

simon.spika@uni-konstanz.de

1 Department of Economics, University of Konstanz, Box 135, 78457 Konstanz, Germany some of which also increase contemporaneous health care utilization. Examples are adverse events of sport activities like injuries, muscular damage, weakening of the immune system due to highly intense training (Lynch et al. 2019) and psychosomatic symptoms like eating disorders (Verhagen et al. 2012). In fact, evidence on this association is less clear. Although a recent review suggests that a negative relationship between PA and health care expenditures is found in the majority of studies (Ding et al. 2017), no significant association (Chevan and Roberts 2014; Karl et al. 2018) or a positive relationship (Kang and Xiang 2017; Lynch et al. 2019) is reported in some cases. Ding et al. (2017) argue that it is problematic to compare the estimates of the effect of PA, partially because of methodological differences between studies. An important issue is how the measure of PA actually is defined. Specifically there is no consensus how the different domains (i.e., leisure time, travel, transport) are considered in the measure of PA. This gives rise to the question whether PA needs to be assessed for each domain separately or whether it is sufficient to assess total PA aggregated across all domains, as it is done for example in the 
US Medical Expenditure Survey MEPS (MEPS HC AP) analyzed in several studies (Kang and Xiang 2017; ValeroElizondo et al. 2016). Clearly, if it does not matter for the effect of PA in which domain it is exerted, assessing total PA without differentiating by domain is sufficient. But if for example PA during occupation time does not have the same health effects as PA during leisure time, as argued by Holtermann et al. (2018), a measure which aggregates physical activity across domains is not suitable.

Domain-specific associations with the risk of various health outcomes are addressed in a number of studies, e.g., obesity (Abu-Omar and Rütten 2008; Chu and Moy 2013; Petermann-Rocha et al. 2019; Sarma et al. 2015), high blood pressure (Chu and Moy 2013; Petermann-Rocha et al. 2019; Sarma et al. 2015), elevated blood glucose or diabetes (Chu and Moy 2013; Petermann-Rocha et al. 2019; Sarma et al. 2015) or heart disease (Sarma et al. 2015). Overall evidence from these studies suggests that leisure time PA is associated with a lower risk for these outcomes, while occupational PA is less likely to reduce the occurrence. Likewise in a meta-analysis of over twenty prospective studies, Li et al. (2013) report a negative effect of leisure time PA, but a weakly positive effect of occupational activity on the risk of cardiovascular disease.

In contrast, studies addressing domain-specific effects of PA on effective health care utilization or expenditures are rare. An exception is the study by Codogno et al. (2015), where PA was assessed on the three domains occupation, sport and non-sport in a population of about 1000 patients aged 50 years or over, registered in Brazilian health care units. Codogno et al. (2015) analyzed the association of PA in the different domains with different kinds of health care expenditures and found that occupational activity and sport were negatively associated with drug expenditures, while for overall expenditures a significant negative association is reported with non-sport activities. Clearly not only because of the specific population analyzed by Codogno et al. (2015), more evidence on the domain specific effects of physical activity on contemporaneous health care utilization is needed.

The aim of this study is to assess and to compare the association of PA with contemporaneous health care utilization, namely the number of physician visits for the population of a German cohort study, when PA is considered either with a measure that aggregates across domains or with a measure that differentiates between PA in different domains.

\section{Methods}

\section{Data sample}

The data were retrieved from the Konstanz Life-Study, a longitudinal cohort study for individuals aged 18+ conducted in the region of Konstanz, a mid-sized city in southern Germany. The study was launched in spring 2012 as part of the EATMOTIVE project funded by the German Federal Ministry of Education and Research. For the Konstanz Life-Study data were collected at a central site (city center), participants were recruited via flyers, posters, and newspaper articles (Klusmann et al. 2016). Due to data requirements, for the present analysis the observations from waves 2016 and 2017 are used in a pooled sample, encompassing 2096 observations.

\section{Dependent variable}

The number of visits to any physician (including specialist) in the last 3 months before the date of the interview was used as an indicator for outpatient health care utilization. This definition is similar to the one formulated in the representative German Socio-Economic Panel (SOEP) (Reber et al. 2018; Greiner et al. 2018). The time span of 3 months is frequently used for nonurgent ambulatory visits to minimize recall bias and underreporting (Bhandari and Wagner 2006).

\section{Explanatory variables}

PA was measured with the Global Physical Activity Questionnaire (GPAQ), which was developed by the WHO as an instrument to monitor physical activity at the population level (Bull et al. 2009; WHO 2016). The GPAQ has been shown to have reasonable reliability (Bull et al. 2009; Riviere et al. 2018) and, as compared to the more widely used International Physical Activity Questionnaire (IPAQ) as well as to accelerometer assessed physical activity, reasonable validity (Cleland et al. 2014; Riviere et al. 2018). With the GPAQ, the participant is asked how much time he or she spends in a normal week on moderate and vigorous PA during leisure-time (LTPA), work-time (WTPA) and for the time spent with walking or biking for travel purposes (TTPA). We assigned each observation to one of the three activity levels "highly active," "moderately active" or "low active" according to the criteria defined by "IPAQ analysis framework" (Sjöström et al. 2006; Wallmann-Sperlich and Froboese 2014). To be "highly active" an individual either must exert vigorous PA on at least 3 days per week accumulating at least 1500 MET-minutes (the equivalent energy expenditure 
associated with 1500 min sitting) or must exert any combination of walking, moderate or vigorous PA accumulating at least 3000 MET-minutes per week. A "moderately active" individual exerts either vigorous PA of at least 20 min on 3 or more days per week or moderate PA and/or walking of at least 30 min per day on 5 or more days or any combination of walking, moderate or vigorous PA activities on 5 or more days achieving a minimum of at least 600 MET-minutes/week. The category "low active" entails individuals not meeting any of the criteria for the "highly active" or "moderately active" level and also includes individuals exerting no PA at all.

Based on this categorization, we derived two measures of PA. The first measure is suggested by the IPAQ guidelines and categorizes individuals according to total PA aggregated across the three domains. With the second measure, in contrast, each observation is assigned to three domain related categories, according to PA achieved in the single domains. For example, an individual who achieved 600 MET-minutes with three bouts of at least $20 \mathrm{~min}$ vigorous activity during leisure time but who exerts no TTPA or WTPA is assigned to the moderate LTPA category and to the low active category for TTPA and WTPA. The categorization according to the IPAQ guidelines is most suitable for the main purpose of this study. Because it relies not only on energy expenditure or time-as suggested, e.g., by the WHO recommendations (WHO 2016)_but also considers the frequency of PA, and because it comprises three activity levels, it offers sufficient homogeneity on the same activity level between the different domains needed for comparison.

With the differentiated measure, however, the moderate and high WTPA categories contain very few observations (s. Table 1) and we therefore clustered the observations in a single "at least moderate" category. As this category contains moderately and highly active individuals in more or less equal shares, the comparability with, e.g., moderate LTPA as well as high LTPA is impaired. Also the high TTPA category contains very few observations. For practical reasons we assigned those observations to the moderate TTPA category. But because of the negligible number of highly active individuals during travel time in relation to the number of moderately individuals, the comparability to the moderate LTPA category is not impaired in this case.

We controlled for a number of further covariates. Selfassessed health status was included by three dummy variables, indicating whether an individual rates own health as "poor/very poor," "fair" or "good/very good." We also included a dummy variable indicating whether the individual had a physician visit due to one of sixteen chronical diseases. In addition we controlled for education (using a binary variable indicating whether the individual has a high school degree required to attend a university, i.e., a degree like the German "Abitur”), gender, age, smoking, alcohol consumption, occupation, income, children aged below 14 years in household, waist-to-hip ratio and a time dummy indicating the year 2017.

\section{Data analysis}

To account for gender differences, the analysis was conducted for women and men separately. To assess the effect of PA on physician visits, we estimated negative binomial models with exponential mean function. Because our dependent variable is overdispersed in the data (i.e., the variance of physician visits exceeds the mean), the negative binomial estimator provides a more efficient estimation than the Poisson quasi-maximum likelihood estimator (Cameron and Trivedi 2013). As there are only 33\% observations from individuals who participated in both waves 2016 and 2017, we did not employ panel techniques but report cluster robust standard errors.

We analyzed three specifications of the negative binomial model. All specifications include the same set of control variables, but differ in the variables representing PA. In Specification 1 the aggregate measure of PA is included. The differentiated measure is considered with Specification 2. Specification 3 finally uses the differentiated measure of Specification 2, but additionally includes interaction terms between the LTPA and TTPA on the respective levels. With Specification 3 we are able to identify the "pure" domain effects, because the regression coefficient for a particular domain/level category (e.g., moderate LTPA) represents the effect for an individual who is active on this particular domain but only low active on the other two domains. We used the Chi-square Wald test to test whether the coefficient estimates for PA in the single domains in Specification 3 are different from the coefficients for total PA in Specification 1. Since the aggregate measure in Specification 1 assumes that it does not matter for the effect of PA on which domain it is actually exerted, the estimates should not be different in both specifications.

All calculations were carried out with $\mathrm{R}$ version 3.6.1.

\section{Results}

\section{Descriptive analysis}

In our sample 1330 (63\%) observations are female, 776 $(37 \%)$ are male. The mean age for women is 39.9 years, for men 43.1 years. The mean number of visits is higher among women than among men (1.62 vs. 1.18). In the domain of leisure time, $48 \%$ of women are low active while $36 \%$ are highly active. Men appear to exert more 
Table 1 Sample description

\begin{tabular}{|c|c|c|c|}
\hline Variable & Total $(n=2096)$ & Women $(n=1330)$ & $\operatorname{Men}(n=766)$ \\
\hline Age & $41.07(17.16)$ & $39.91(16.38)$ & $43.1(18.27)$ \\
\hline High school degree & $1531(0.73)$ & $985(0.74)$ & $546(0.71)$ \\
\hline \multicolumn{4}{|l|}{ Occupation } \\
\hline Employed/self-employed & $1133(0.54)$ & $732(0.55)$ & $401(0.52)$ \\
\hline Student/vocational training & $627(0.3)$ & $417(0.31)$ & $210(0.27)$ \\
\hline Unemployed & $37(0.02)$ & $21(0.02)$ & $16(0.02)$ \\
\hline Retired & $263(0.13)$ & $129(0.1)$ & $134(0.17)$ \\
\hline Homemaker & $36(0.02)$ & $31(0.02)$ & $5(0.01)$ \\
\hline \multicolumn{4}{|l|}{ Income } \\
\hline$<1000 \mathrm{EUR} / \mathrm{month}$ & $490(0.23)$ & $340(0.26)$ & $150(0.2)$ \\
\hline 1000-2000 EUR/month & $425(0.2)$ & $313(0.24)$ & $112(0.15)$ \\
\hline 2000-3000 EUR/month & $403(0.19)$ & $256(0.19)$ & $147(0.19)$ \\
\hline 3000-5000 EUR/month & $478(0.23)$ & $261(0.2)$ & $217(0.28)$ \\
\hline$>5000 \mathrm{EUR} / \mathrm{month}$ & $300(0.14)$ & $160(0.12)$ & $140(0.18)$ \\
\hline Kids age $<14$ & $0.12(0.33)$ & $0.12(0.32)$ & $0.14(0.35)$ \\
\hline \multicolumn{4}{|l|}{ Health status } \\
\hline Poor/very poor & $96(0.05)$ & $66(0.05)$ & $30(0.04)$ \\
\hline Fair & $386(0.18)$ & $231(0.17)$ & $155(0.2)$ \\
\hline Good/very good & $1614(0.77)$ & $1033(0.78)$ & $581(0.76)$ \\
\hline Phys. visits due to chron. disease $y / n$ & $359(0.17)$ & $230(0.17)$ & $129(0.17)$ \\
\hline Waist-to-hip ratio & $84.86(11.28)$ & $81.36(10.35)$ & $90.95(10.18)$ \\
\hline Smoker & $317(0.15)$ & $173(0.13)$ & $144(0.19)$ \\
\hline \multicolumn{4}{|l|}{ Alcohol consumption } \\
\hline$<100 \mathrm{~g}$ alc/week & $1668(0.8)$ & $1136(0.85)$ & $532(0.69)$ \\
\hline 100-200 g alc/week & $252(0.12)$ & $125(0.09)$ & $127(0.17)$ \\
\hline 200-350 g alc/week & $133(0.06)$ & $53(0.04)$ & $80(0.1)$ \\
\hline $2>350 \mathrm{~g}$ alc/week & $43(0.02)$ & $16(0.01)$ & $27(0.04)$ \\
\hline No. physician visits & $1.46(1.9)$ & $1.62(1.96)$ & $1.18(1.76)$ \\
\hline \multicolumn{4}{|l|}{ LTPA } \\
\hline Low & $960(0.46)$ & $636(0.48)$ & $324(0.42)$ \\
\hline Moderate & $319(0.15)$ & $209(0.16)$ & $110(0.14)$ \\
\hline High & $817(0.39)$ & $485(0.36)$ & $332(0.43)$ \\
\hline \multicolumn{4}{|l|}{ TTPA } \\
\hline Low & $1088(0.52)$ & $655(0.49)$ & $433(0.57)$ \\
\hline Moderate & $978(0.47)$ & $656(0.49)$ & $322(0.42)$ \\
\hline High & $30(0.01)$ & $19(0.01)$ & $11(0.01)$ \\
\hline \multicolumn{4}{|l|}{ WTPA } \\
\hline Low & $1873(0.89)$ & $1190(0.89)$ & $683(0.89)$ \\
\hline Moderate & $124(0.06)$ & $81(0.06)$ & $43(0.06)$ \\
\hline High & $99(0.05)$ & $59(0.04)$ & $40(0.05)$ \\
\hline \multicolumn{4}{|l|}{ Total physical activity } \\
\hline Low & $235(0.11)$ & $142(0.11)$ & $93(0.12)$ \\
\hline Moderate & $835(0.4)$ & $566(0.43)$ & $269(0.35)$ \\
\hline High & $1026(0.49)$ & $622(0.47)$ & $404(0.53)$ \\
\hline
\end{tabular}

Means or frequencies (standard deviations or percentages). Data from the Konstanz Life-Study, waves 2016 and 2017, Germany

LTPA leisure time physical activity, TTPA travel time physical activity, WTPA working time physical activity 
LTPA, as $42 \%$ are low active but $43 \%$ are highly active. For both genders, the moderate LTPA category contains the lowest number of observations (16\% resp. 14\%). In contrast, women are more physically active for travel purposes, as $49 \%$ of women are in the moderate TTPA category and $49 \%$ in the low active category, while $42 \%$ of men are in the moderate and $57 \%$ in the low active category. Only $1 \%$ of women and men are highly active in the travel domain. In the working domain, $89 \%$ of women and men are low, $6 \%$ moderately and $4-5 \%$ are highly active. When PA is aggregated across the three domains, only $11 \%$ of women and $12 \%$ of men are categorized as low active. In contrast, $43 \%$ and $35 \%$ are in the moderate and $47 \%$ and $53 \%$ are in the high activity category, respectively. Table 1 provides the description of all variables used.

\section{Regression analysis}

The estimation results for the coefficient estimates of the PA dummies and the interaction terms of the Negbin models are given in Table 2 (women) and Table 3 (men). The estimation results for all variables are given in Tables S1 and S2 in the supplementary material.

\section{Women}

In Specification 1 with total PA aggregated across domains the coefficient estimates for moderate and high total PA are low in magnitude and not significant for women (Table 2). In Specification 2, considering PA by domain, both coefficient estimates for LTPA are positive and comparably large in magnitude, but only the coefficient for high LTPA is significant. Because of the exponential mean function in the negative binomial model, the coefficient estimate of 0.15 indicates $16 \%(=\exp (0.15)-1, \mathrm{CI}[+2 \%,+33 \%])$ more visits for women who are highly active during leisure time compared to women, who are low active in the leisure time domain. Moderate TTPA is associated with 5\% fewer visits, which is not significantly different from zero (CI $[-16 \%,+8 \%])$, and the coefficient for at least moderate WTPA is negligible in magnitude.

In Specification 3, where the interaction between domains is considered and the PA dummies identify the effect of PA solely exerted in the respective domain, the coefficient for high LTPA indicates that women who are highly active during leisure time but low active in the travel and working domains have $22 \%$ (CI [+ $2 \%$, $+46 \%]$ ) more visits than women who are low active in all domains. It is noteworthy that by the negative coefficient of
Table 2 Estimation results negative binomial model, women

\begin{tabular}{|c|c|c|c|}
\hline Independent variables & Specification 1 & Specification 2 & Specification 3 \\
\hline \multicolumn{4}{|l|}{ Total PA (ref.: Low) } \\
\hline Moderate & $-0.03(0.10)$ & - & - \\
\hline High & $0.04(0.10)$ & - & - \\
\hline \multicolumn{4}{|l|}{ LTPA (ref.: Low) } \\
\hline Moderate & - & $0.11(0.09)$ & $0.11(0.14)$ \\
\hline High & - & $0.15^{*}(0.07)$ & $0.20 *(0.09)$ \\
\hline \multicolumn{4}{|l|}{ TTPA (ref.: Low) } \\
\hline Moderate & - & $-0.05(0.06)$ & $-0.02(0.09)$ \\
\hline \multicolumn{4}{|l|}{ WTPA (ref.: Low) } \\
\hline At least moderate & - & $0.01(0.16)$ & $-0.37+(0.21)$ \\
\hline \multicolumn{4}{|l|}{ Interactions } \\
\hline LTPA $\bmod \times$ TTPA $\bmod$ & - & - & $-0.02(0.19)$ \\
\hline LTPA high $\times$ TTPA mod & - & - & $-0.15(0.13)$ \\
\hline LTPA $\bmod \times$ WTPA act & - & - & $0.09(0.29)$ \\
\hline LTPA high $\times$ WTPA act & - & - & $0.33(0.33)$ \\
\hline TTPA mod $\times$ WTPA act & - & - & $0.36(0.29)$ \\
\hline$n$ & 1330 & 1330 & 1330 \\
\hline Akaike Information Criterion & 4473.4 & 4473.9 & 4474.7 \\
\hline
\end{tabular}

Dependent variable: number of physician visits. Data from the Konstanz Life-Study, waves 2016 and 2017, Germany

Shown are only estimates for variables associated with physical activity

$+p<0.1, * p<0.05$, cluster-robust standard errors in parentheses

LTPA leisure time physical activity, TTPA travel time physical activity, WTPA working time physical activity 
Table 3 Estimation results negative binomial model, men

\begin{tabular}{llll}
\hline Independent variables & Specification 1 & Specification 2 & Specification 3 \\
\hline Total PA (ref.: Low) & & & - \\
Moderate & $0.02(0.14)$ & - & - \\
High & $0.04(0.14)$ & - & $-0.19(0.21)$ \\
LTPA (ref.: Low) & & & $-0.02(0.16)$ \\
Moderate & - & $-0.04(0.15)$ & \\
High & - & & $-0.10(0.11)$ \\
TTPA (ref.: Low) & - & $0.05(0.10)$ & $-0.35(0.22)$ \\
Moderate & - & & $0.23(0.28)$ \\
WTPA (ref.: Low) & & $-0.16(0.14)$ & $0.14(0.21)$ \\
At least moderate & - & - & $0.48(0.43)$ \\
Interactions & - & - & $-0.23(0.31)$ \\
LTPA mod $\times$ TTPA mod & - & - & $0.39(0.27)$ \\
LTPA high $\times$ TTPA mod & - & - & 766 \\
LTPA mod $\times$ WTPA act & - & - & 2235.5 \\
LTPA high $\times$ WTPA act & 766 & 2230.3 & \\
TTPA mod $\times$ WTPA act & 2227.2 & &
\end{tabular}

Dependent variable: number of physician visits. Data from the Konstanz Life-Study, waves 2016 and 2017, Germany

Shown are only estimates for variables associated with physical activity

$+p<0.1,{ }^{*} p<0.05$, cluster-robust standard errors in parentheses

LTPA leisure time physical activity, TTPA travel time physical activity, WTPA working time physical activity

the respective interaction term "LTPA high x TTPA mod" moderate TTPA mitigates the positive effect of LTPA. The coefficient estimate for WTPA is significant at the $10 \%$ level, indicating $31 \%$ (CI $[-54 \%,+5 \%]$ ) fewer visits for women who are only active for working purposes compared to low active women. However, as only 27 women are in this group, these estimates should be interpreted with caution.

The Wald test rejects at the $10 \%$ level $(p$ value $=0.075)$ the null hypothesis that the coefficient estimate for high LTPA in Specification 3 is not different from the estimate for high total PA in Specification 1. The estimates for moderate LTPA or moderate TTPA in Specification 3 in contrast are found not to be significantly different from the coefficient of moderate total PA in Specification 1 ( $p$ values 0.27 and 0.96 , respectively).

\section{Men}

For the male sample, none of the coefficients for either PA dummy is significant in any of the three specifications (Table 3). In Specification 1, as in the case of women, both coefficients for total PA are negligible. In contrast to women, both LTPA coefficients in Specification 2 are very low in magnitude, while the estimate for the WTPA coefficient is relatively high and indicates $15 \%$ fewer visits for men who are at least moderately active during working time. However, due also to large standard errors, the association is not significant (CI $[-36 \%,+12 \%])$. For men, all coefficients for physical activity in Specification 3 are negative for all domains and, except for high LTPA, relatively large. In particular being at least moderately active only during leisure time or during working time is associated with $17 \%$ (CI $[-45 \%,+24 \%]$ ) or $30 \%$ (CI $[-54 \%,+8 \%])$ fewer visits, respectively. However, again because of the large standard errors, the associations are not significant at the $10 \%$ level. The Wald test did neither detect a significant difference between the coefficients for moderate LTPA or moderate TTPA in Specification 3 and moderate total PA in Specification 1 ( $p$ values 0.31 and 0.44 , respectively), nor between high LTPA in Specification 3 and high total PA in Specification 1 ( $p$ value 0.69). Also none of the sums of a PA dummy coefficient with the coefficient of the respective interaction term is significant.

\section{Discussion}

With this study, we exploit the comprehensive assessment offered by the GPAQ questionnaire to analyze and compare the associations of PA with the number of 
contemporaneous physician visits, when physical activity is either considered with a measure which aggregates activity across domains or with a measure that differentiates between domains.

First our study highlights that gender differences in the association between PA and health care utilization are relevant and in this respect confirms findings of other studies where gender-specific effects are accounted for (Anderson et al. 2005; Gil et al. 2018; Yen 2012). In our study we found no significant association between either measure of PA and physician visits among the male participants of the Konstanz Life-Study. However, as suggested by the estimates in Specification 3, being active in one domain only is more likely to be negatively than positively associated with the number of visits for men. For women, in contrast, while no association can be detected with the aggregate measure either, domain-specific effects can be identified with the differentiated measure for LTPA: High LTPA is positively associated with the number visits, but this effect is mitigated for women who are also active during travel time. Further the assumption that the effect of physical activity in a single domain is not different from the effect of total PA, which is necessary for the aggregate measure to be appropriate, cannot be upheld at least for LTPA. Therefore, our results advocate the use of the differentiated measure rather than the aggregate measure for analyzing the association between PA and contemporaneous health care utilization.

The detailed assessment of physical activity in different domains however requires comparably long questionnaires (for the Konstanz Life-Study the GPAQ administered encompasses 16 questions) and might be too cumbersome for large household surveys. This is probably the reason why several studies are restricted to LTPA only (Arem et al. 2015; Carlson et al. 2015; Karl et al. 2018). Therefore, it might be interesting what our results would have looked like, if Specification 2 had been estimated with only including LTPA, but not TTPA and WTPA. It turns out that the coefficient estimates for moderate and high LTPA are not very different from the estimates with additionally TTPA and WTPA included (s. Table S3, supplementary material) suggesting that assessing LTPA only results in acceptable estimates for portraying the association of physical activity and physician visits.

In our study we found that high leisure time activity increases physician visits by more than $16 \%$ among women. Although this result is in contrast with the findings by Sari (2009), who analyzed Canadian data, it is consistent with the findings by Kang and Xiang (2017) for USMEPS data, who report an increased odds ratio of having an office based visit for active individuals. Our findings are also consistent with two studies using data from the representative German Socio-Economic Panel, with one study reporting a significant (Eibich and Ziebarth 2014) and the other study reporting an insignificant positive association (Winkelmann 2004) of regular sport with the number of physician visits. However, none of these studies account for gender differences in the association of physical activity with physician visits. To clarify the external validity of our results, we defined a new dummy variable which indicates whether at least $60 \mathrm{~min}$ of vigorous activity per week is accumulated and which resembles the physical activity variable in the SOEP sample (Sport once a week). We regressed this variable on physician visits in a NegBin Model using the complete sample (men and women). The results indicate an insignificant increase by $5.6 \%$ of visits for "active" individuals (s. Table S3, supplementary material), which is very close to the insignificant increase of $4.6 \%$ reported by Winkelmann (2004).

We can only speculate on the reasons for this positive relationship between high LTPA and physician visits among the female participants of the Konstanz-Life study. Three explanations are commonly discussed. First, vigorous activity and sport are associated with increased risk for damage of body tissue and cardiovascular events (Verhagen et al. 2012). However, if this was a major reason here, the positive association should be evident also among men. Second, physically active people are reported to use preventive health care services and checkups more often than inactive people (Kang and Xiang 2017), maybe because they are more health conscious. However, also this explanation presumes that only women are affected by this association, but evidence suggests also a positive association between physical activity and prostate cancer screening (Kang and Xiang 2017). The third explanation can be seen in an unhealthy quest for lowering body fat among young women and the symptoms of so called female triad - a combination of eating disorders, amenorrhea and osteoporosis, which is observed among high-level female athletes - can also be found in a general active female population (Verhagen et al. 2012; Milano et al. 2020). This hypothesis is supported inasmuch as the positive association between high LTPA and visits is strongest among the younger female participants of the Konstanz-Life Study with low body mass index (s. Table S3, supplementary material). In any case, our results provides additional evidence that LTPA is not necessarily associated with lower health care utilization.

\section{Limitations}

We are aware of several limitations of our study. First, due to data restrictions we are limited to analyzing the domainspecific effects of physical activity to physician visits only. But other kinds of health care services are affected by physical activity as well. In particular, those studies where 
a positive association with physician visits was found, at the same time report a negative association with inpatient visits (Kang and Xiang 2017; Eibich and Ziebarth 2014). Secondly, the mere number of physician visits does not allow inferring unambiguously the actual health care cost associated, as for example medications prescribed by the doctor may differ. However, among those female participants of the Konstanz Life Study who had a physician visit, no difference is evident in the number of medications, taken on a regular basis for thirteen medical conditions (hypertension, diabetes, sedative, etc.), when we compare women with high or moderate LTPA with those with low LTPA (not shown). Third, because of the cross-sectional data, the estimated associations between physical activity and physician visits may not reflect true causality because of unobserved factors like health consciousness. Longitudinal data would provide the most reliable way to control for such unobserved factors. But as longitudinal data are difficult and costly to acquire, much would be gained if further information on the diagnosis or the kind of treatment was regularly collected along cross-sectional studies, so that more could be learned about the causal effects of physical activity on contemporaneous health care utilization.

\section{Conclusions}

Among the female participants of the Konstanz Life-Study, high physical activity during leisure time is associated with an increased number of contemporaneous physician visits. As this effect is different from the effect of high total physical activity, the results reject the aggregate measure to be appropriate for analyzing the relationship between physical activity and contemporaneous health care utilization. The results also suggest that possible positive effects on health care utilization should be taken into account in attempts to foster leisure time physical activity.

Acknowledgements Open Access funding provided by Projekt DEAL. We thank two anonymous reviewers for valuable comments.

Funding This study was funded by the German Federal Ministry of Education and Research within the project SmartAct (Grant 01EL1420A).

\section{Compliance with ethical standards}

Conflict of interest The authors declare that they have no conflict of interest.

Ethical approval Full ethical approval for the Konstanz Life-Study was obtained from the University of Konstanz Local Research Ethics Committee on February 10, 2012.
Open Access This article is licensed under a Creative Commons Attribution 4.0 International License, which permits use, sharing, adaptation, distribution and reproduction in any medium or format, as long as you give appropriate credit to the original author(s) and the source, provide a link to the Creative Commons licence, and indicate if changes were made. The images or other third party material in this article are included in the article's Creative Commons licence, unless indicated otherwise in a credit line to the material. If material is not included in the article's Creative Commons licence and your intended use is not permitted by statutory regulation or exceeds the permitted use, you will need to obtain permission directly from the copyright holder. To view a copy of this licence, visit http://creativecommons. org/licenses/by/4.0/.

\section{References}

Abu-Omar K, Rütten A (2008) Relation of leisure time, occupational, domestic, and commuting physical activity to health indicators in Europe. Prev Med 47:319-323. https://doi.org/10.1016/j. ypmed.2008.03.012

Anderson LH, Martinson BC, Crain AL, Pronk NP, Whitebird RR, O'Connor PJ, Fine LJ (2005) Health care charges associated with physical inactivity, overweight, and obesity. Prev Chronic Dis 2:A09

Arem $\mathrm{H}$ et al (2015) Leisure time physical activity and mortality: a detailed pooled analysis of the dose-response relationship. JAMA Int Med 175:959-967. https://doi.org/10.1001/jamain ternmed.2015.0533

Bhandari A, Wagner T (2006) Self-reported utilization of health care services: improving measurement and accuracy. Med Care Res Rev 63:217-235. https://doi.org/10.1177/1077558705285298

Bouchard C, Blair SN, Haskell WL (2012) Physical activity and health, 2nd edn. Human Kinetics, Champaign

Bull FC, Armstrong TP, Dixon T, Hamm S, Neiman A, Pratt M (2004) Physical inactivity. In: World Health Organization (ed) Comparative quantification of health risks. World Health Organization, Geneva

Bull FC, Maslin TS, Armstrong T (2009) Global Physical Activity Questionnaire (GPAQ): nine country reliability and validity. Study J Phys Act Health 6:790-804. https://doi.org/10.1123/ jpah.6.6.790

Cameron AC, Trivedi PK (2013) Regression analysis of count data, 2nd edn. Cambridge University Press, Cambridge

Carlson SA, Fulton JE, Pratt M, Yang Z, Adams EK (2015) Inadequate physical activity and health care expenditures in the United States. Prog Cardiovasc Dis 57:315-323. https://doi. org/10.1016/j.pcad.2014.08.002

Chevan J, Roberts DE (2014) No short-term savings in health care expenditures for physically active adults. Prev Med 63:1-5. https://doi.org/10.1016/j.ypmed.2014.02.020

Chu AHY, Moy FM (2013) Associations of occupational, transportation, household and leisure-time physical activity patterns with metabolic risk factors among middle-aged adults in a middleincome country. Prev Med 57:S14-S17. https://doi.org/10.1016/ j.ypmed.2012.12.011

Cleland CL, Hunter RF, Kee F, Cupples ME, Sallis JF, Tully MA (2014) Validity of the Global Physical Activity Questionnaire (GPAQ) in assessing levels and change in moderate-vigorous physical activity and sedentary behaviour. BMC Public Health 14:11. https://doi.org/10.1186/1471-2458-14-1255

Codogno JS, Turi BC, Kemper HCG, Fernandes RA, Christofaro DGD, Monteiro HL (2015) Physical inactivity of adults and 
1-year health care expenditures in Brazil. Int J Public Health 60:309-316. https://doi.org/10.1007/s00038-015-0657-z

Ding D, Kolbe-Alexander T, Nguyen B, Katzmarzyk PT, Pratt M, Lawson KD (2017) The economic burden of physical inactivity: a systematic review and critical appraisal. Br J Sports Med 51:1392-1409. https://doi.org/10.1136/bjsports-2016-097385

Eibich P, Ziebarth NR (2014) Analyzing regional variation in health care utilization using (rich) household microdata. Health Policy (Amst, Neth) 114:41-53. https://doi.org/10.1016/j.healthpol. 2013.04.015

Gil J, Sicras-Mainar A, Zucchelli E (2018) Uncontrolled diabetes and health care utilisation: panel data evidence from Spain. Eur J Health Econ 19:785-795. https://doi.org/10.1007/s10198-0170920-8

Greiner GG, Schwettmann L, Goebel J, Maier W (2018) Primary care in Germany: access and utilisation-a cross-sectional study with data from the German Socio-Economic Panel (SOEP). BMJ Open 8:e021036. https://doi.org/10.1136/bmjopen-2017021036s

Holtermann A, Krause N, van der Beek AJ, Straker L (2018) The physical activity paradox: six reasons why occupational physical activity (OPA) does not confer the cardiovascular health benefits that leisure time physical activity does. Br J Sports Med 52:149. https://doi.org/10.1136/bjsports-2017-097965

Kang S, Xiang X (2017) Physical activity and health services utilization and costs among U.S. adults. Prev Med 96:101-105. https://doi.org/10.1016/j.ypmed.2016.12.043

Karl FM et al (2018) Direct healthcare costs associated with device assessed and self-reported physical activity: results from a crosssectional population-based study Bmc. Public Health 18:11. https://doi.org/10.1186/s12889-018-5906-7

Klusmann V, Musculus L, Sproesser G, Renner B (2016) Fulfilled emotional outcome expectancies enable successful adoption and maintenance of physical activity. Front Psychol. https://doi.org/ 10.3389/fpsyg.2015.01990

Li J, Loerbroks A, Angerer P (2013) Physical activity and risk of cardiovascular disease: what does the new epidemiological evidence show? Curr Opin Cardiol 28:575-583. https://doi.org/ 10.1097/HCO.0b013e328364289c

Lynch KR et al (2019) Impact of sports participation on incidence of bone traumatic fractures and health-care costs among adolescents: ABCD-Growth Study. Physician Sportsmed. https://doi. org/10.1080/00913847.2019.1685859

Maruti SS, Willett WC, Feskanich D, Rosner B, Colditz GA (2008) A prospective study of age-specific physical activity and premenopausal breast cancer. J Natl Cancer Inst 100:728-737. https://doi.org/10.1093/jnci/djn135

Meisinger C, Lowel H, Heier M, Kandler U, Doring A (2007) Association of sports activities in leisure time and incident myocardial infarction in middle-aged men and women from the general population: the MONICA/KORA Augsburg cohort study. Eur J Cardiovasc Prev Rehabil 14:788-792
Milano W, Milano L, Capasso A (2020) Eating disorders in athletes: from risk management to therapy. Endocr Metab Immune Disord-Drug Targets 20:2-14. https://doi.org/10.2174/ 2871530329666190428121446

Petermann-Rocha F et al (2019) Association of leisure time and occupational physical activity with obesity and cardiovascular risk factors in Chile. J Sports Sci. https://doi.org/10.1080/ 02640414.2019.1647738

Reber KC, König H-H, Hajek A (2018) Leadership position and physician visits - results of a nationally representative longitudinal study in Germany. J Occup Med Toxicol 13:33. https://doi. org/10.1186/s12995-018-0216-7

Riviere F, Widad FZ, Speyer E, Erpelding ML, Escalon H, Vuillemin A (2018) Reliability and validity of the French version of the global physical activity questionnaire. J Sport Health Sci 7:339-345. https://doi.org/10.1016/j.jshs.2016.08.004

Sari N (2009) Physical inactivity and its impact on healthcare utilization. Health Econ 18:885-901

Sarma S, Devlin RA, Gilliland J, Campbell MK, Zaric GS (2015) The effect of leisure-time physical activity on obesity, diabetes, high bp and heart disease among canadians: evidence from 2000/2001 to 2005/2006. Health Econ 24:1531-1547

Sjöström M, Oja P, Hagströmer M, Smith BJ, Bauman A (2006) Health-enhancing physical activity across European Union countries: the Eurobarometer study J. Public Health 14:291-300. https://doi.org/10.1007/s10389-006-0031-y

Sundquist K, Qvist J, Johansson S-E, Sundquist J (2005) The longterm effect of physical activity on incidence of coronary heart disease: a 12-year follow-up study. Prev Med 41:219-225. https://doi.org/10.1016/j.ypmed.2004.09.043

Valero-Elizondo $\mathrm{J}$ et al (2016) Economic impact of moderatevigorous physical activity among those with and without established cardiovascular disease: 2012 medical expenditure panel survey. J Am Heart Assoc 5:11. https://doi.org/10.1161/ jaha.116.003614

Verhagen EALM, van Sluijs EMF, van Mechelen W (2012) Risks of physical activity. In: Bouchard C, Blair SN, Haskell WL (eds) Physical activity and health, 2nd edn. Human Kinetics, Champaign

Wallmann-Sperlich B, Froboese I (2014) Physical activity during work, transport and leisure in Germany-prevalence and sociodemographic correlates. PloS ONE 9:e112333. https://doi.org/ 10.1371/journal.pone.0112333

WHO (2016) Global Physical Activity Questionnaire (GPAQ) analysis guide

Winkelmann R (2004) Health care reform and the number of doctor visits-an econometric analysis. J Appl Econom 19:455-472

Yen ST (2012) Gender differences, physical activity and body weight. Appl Econ 44:3921-3934

Publisher's Note Springer Nature remains neutral with regard to jurisdictional claims in published maps and institutional affiliations. 